\title{
ХУДОЖЕСТВЕННАЯ КУЛЬТУРА В ПРОЦЕССАХ ФОРМИРОВАНИЯ ГРАЖДАНСКОЙ ИДЕНТИЧНОСТИ
}

\author{
3.В. Канукова \\ Б.В. Туаева \\ 3.Т. Плиева
}

Исследование выполнено в рамках Программы фундаментальных научных исследований Президиума РАН «Историческая память и российская идентичность»

В статье рассматривается российская художественная культура второй половинь XIX - начала XX в. как важная составляющая исторического опыта формирования российской гражданской нации на Северном Кавказе. Актуальность исследования определяется востребованностью исторического опыта соицально-политической и культурной интеграчии народов Северного Кавказа в российское общество и государство, в современных проиессах формирования российской гражданской идентичности. Сегодня эта проблема актуализирована государственной национальной политикой, задачами которой являются согласование государственных и начионально-культурных интересов народов Российской Федерации, создание условий для утверждения общегражданской идентичности - российской нации. Городское пространство Северного Кавказа с его культурными институциями (театр, библиотеки, художественные выставки и др.) исследуется как сфера активного функиионирования российской культуры и русского языка. На основе архивных источников и материалов периодчческой печати выявлены особенности реализаиии функций социальной интеграчии и исторической преемственности художественной культуры, актуализировавщие ее роль в конструировании гражданственности и укреплении российской государственности на Северном Кавказе. Художественная культура как важный компонент исторического сознания активно и вместе с тем не всегда осознанно использовалась в идеологии разных политических режимов. Исследованный исторический опьт позволяет предполагать, ито социальные функиии, формы и ресурсы художественной культуры могут быть успешно использованы в формировании иерархии иенностей современного общества. Среди последних, наряду с моральными и эстетическими иенностями, важная роль отведена гражданскому миру, залогом которого является российская гражданская идентичность. Медийность современного общества имеет мощзный ресурс для пополнения коллективной культурной памяти и исторической традичии новыми формами и символами российской культуры, которые способствует сохранению единства и целостности многонационального Российского государства.

Ключевые слова: художественная культура, культурные институции, государственная политика, российская государственность, гражданская идентичность.

This article deals with Russian art culture in the second half of the XIX-beginning of the XXth century as an important part of the historical experience of forming Russian civil nation in the Northern Caucasus. Relevance of the research is determined by the demand of the historical experience of socio-political and cultural integration of the peoples of the Northern Caucasus in the Russian society and State in modern processes of forming Russian civil identity. Today this problem became national public policy, whose objectives are harmonizing State, national and cultural interests of the peoples of the Russian Federation, creating conditions for the approval of public identity of the Russian nation. Urban space of North Caucasus with its cultural institutions (libraries, theatre, art exhibits, etc.) is regarded as an active sphere of Russian culture and the Russian language functioning. Based on archival sources and materials of periodical press the peculiarities 
of realizating functions of social integration and the historical continuity of artistic culture, its role in constructing citizenship and strengthening the Russian statehood in the North Caucasus are identified. Art culture as an important component of active and historical consciousness, however, was used not always consciously as an ideology tool of different political regimes. Researched historical experience suggests that social functions, forms and resources of artistic culture can be successfully used in the formation of the hierarchy of values in the modern society. Among the latter, along with the moral and aesthetic values the important role is allocated to the civil order, the key to which is the Russian civic identity. Media oriented modern society is a powerful resource for the replenishment of the collective cultural memory and historical tradition with new forms and symbols of the Russian culture, which promotes the preservation of the unity and integrity of the multiethnic Russian State.

Keywords: art culture, cultural institutions, public policy, the Russian statehood, civil identity.

В исторических исследованиях художественная культура, как правило, рассматривается в контексте культурного развития общества - художественного творчества, эстетического воспитания и просвещения, создания, распространения и сохранения материального и духовного культурного наследия.

Гораздо меньше внимания уделялось социальным функциям театрального искусства, литературы, живописи, кинематографа. Существенные перемены в научном понимании художественной культуры произошли с переходом от художественно-критических оценок явлений искусства к исследованиям признаков, параметров и функций художественной культуры, которые превращали искусство в один из важнейших инструментов социальной регуляции жизни общества, включали его в процессы воздействия на сознание людей, в инструментарий государственной политики.

Художественная культура как средство конструирования гражданственности и укреплении государственности оставалась за пределами активного исследовательского внимания. Между тем, интеграционная и информационная функции культуры создают в процессе ее освоения чувство общности, принадлежности к единому кругу и способствуют межпоколенной трансмиссии культурных ценностей, что обеспечивает долгосрочные перспективы их воздействия на социум. Эта функция сохранялась и в условиях смены культурных парадигм в ходе общественных трансформаций.

В последние годы, особенно в рамках Программы Президиума РАН «Историческая память и российская идентичность» выявлены и исследованы многие векторы культурной политики России на Северном Кавказе, работающие на эту задачу - православная культура, образование и просвещение, формирование интеллигенции [1-4 и др.]

Одним из важнейших последствий присоединения Северного Кавказа к Российской империи стала урбанизация, развитие культуры и образования, формирование в среде северокавказских народов интеллигенции, которая выступила в качестве своеобразного проводника образцов мировой культуры, принимала активное участие в общественно-культурной жизни. Общественная динамика пореформенной России предопределила модернизацию традиционных обществ Северного Кавказа, повышение социальной мобильности населения, демократизацию общественной жизни, форсировала интеграцию в российские социально-культурные процессы. Вторая половина XIX века стала важным этапом в становлении и развитии городских поселений на Северном Кавказе, значительная часть которых вырастала из крепостей-форпостов. Города Терской области - Владикавказ, Грозный, Кизляр, Нальчик, Пятигорск, Георгиевск, Моздок - постепенно утрачивали свою первоначаль- 
ную роль военных крепостей и становились административными, экономическими и культурными центрами [5]. Они играли большую роль в установлении российско - северо-кавказских отношений, способствовали интеграции региона в российское экономическое, социальное и культурное пространство.

Приобщение народов Северного Кавказа к городскому образу жизни и культуре требовало знания русского языка. Отмечаемое многими авторами стремление к освоению русского языка среди горцев, и в особенности осетин [6;7] являлось способом адаптации к новым социально-политическим и культурным реалиям. Овладение государственным языком становилось социальным «лифтом» для представителей традиционных обществ, и непременным условием приобщения к городу, в котором русский язык выполнял функции посредника в межэтническом взаимодействии и межкультурной коммуникации.

Городская культура Северного Кавказа, представленная театром, музеями, библиотеками, кинематографом и другими стабильными институциональными формами, развивалась в зоне активного функционирования российской культуры, освоение которой предстояло горцам - горожанам первых поколений.

К началу пореформенного времени в России отмечен рост городов и развитие городской культурной инфраструктуры. К 1870-ым годам в российских городах насчитывалось свыше 100 театральных учреждений, из них около 80 - в европейской части страны $[8,9]$.

Первый русский театр на Кавказе был открыт 1842 году в Ставрополе, быстро завоевав популярность в соседних городах. Театральные гастроли этого театра во Владикавказе произвели столь яркое впечатление, что «жители этого города стали хлопотать об открытии своего театра и просили антрепренера ставрополь- ской труппы помочь подобрать труппу и для будущего Владикавказского театра» $[9,500]$.

Впервые вопрос о владикавказском театре был поставлен в августе 1862 года, когда председатель Владикавказского городского суда Лебедев обратился с официальным прошением к Начальнику Терской области о строительстве «каменного красивой архитектуры театрального здания» $[10,140]$. Лорис-Меликов, известный не только военными подвигами, но и склонностью к «бархатным» методам покорения, приложил немало усилий, убеждая Кавказского наместника Великого князя Михаила в необходимости строительства театра, «призванного облегчить царизму скорейшее духовное покорение горцев» $[8,11]$. Начальник Терской области стал убеждать Главнокомандующего Кавказской армией в необходимости основания русского театра, который имел «перед всеми народными увеселениями то громадное преимушество, что в нем единство интереса публики и общения между собой разноплеменных личностей связывается русской речью, в свою очередь составляюшею вернейшее средство к скорейшему ассимилированию инородиев с господствующею расою» [8,3-9].

31 января 1869 года было получено разрешение Великого Князя Наместника Кавказа на строительство театрального здания. Первое время спектакли проходили в помещении Дворянского собрания или в коммерческом клубе. В 1872 году для театра было построено здание, рассчитанное на 500 мест; в 1874 году впервые во Владикавказском театре появилась профессиональная труппа - «опереточно-драматическая труппа Фальба» [8,21]. В течение многих лет театр сдавался на зимний сезон антрепренерам, а летом оставался в распоряжении городского управления, которое предоставляло здание местным любителям или гастролерам. В 1877 году 
в Городскую думу обратились дворянин Леонард Вейман и артистка Мария Савина с просьбой отдать им театр в аренду бесплатно, но при этом предлагали создать хорошую труппу, навести в театре порядок за свой счет, а в случае необходимости, и за счет городских субсидий [11,86-87; 12,171-174]. В то же время с аналогичным предложением обратились в Городскую думу Сапицкий, Семенов и Тхостов. Они просили отдать в их ведение здание городского театра со всем имуществом и театральной библиотекой, а в случае согласия обязывались сделать ремонт, обновить мебель и костюмы, а когда «признается необходимость» - вернуть все городу [13,30]. Дума дала согласие на это предложение «до появления антрепренеров».

Уже в 1870-х годах современники отмечали, что благотворительные спектакли «решительно вошли в моду» [14,3], что театр внес большие изменения в однообразную жизнь, давал эстетическое наслаждение, способствовал подъему образовательного уровня. Большим праздником для горожан становились гастроли артистов, проезжающих через Владикавказ в Тифлис. Особое впечатление на публику производили гастроли балетной труппы Варшавских театров под управлением директора Шановского, гастроли малороссийских трупп С. Глазуненко, Д. Гайдамаки, талантливых актеров Соколова, Лукашевич, Погодиной-Долинской, примадонны Мариинского театра Бичуриной. Большим успехом пользовалась гастролировавшая в городе тифлисская драматическая труппа, спектакли которой проходили на русском и грузинском языках $[15,71]$. Горожане имели возможность знакомиться с цыганским театральным искусством, японской труппой из Токио и другими $[16,120]$.

В начале 1880 -х годов в театре работала новая драматическая труппа под управлением М. Горского. Единственной профессиональной актрисой в то время была госпожа Горская, которая часто устраивала бенефисы с оперетками. В 1884 году в театре появилась новая актриса Ледковская, с ее участием ставились «Рыцарь без страха и упрека», «Зеленый остров», привлекавшие городскую публику. Массу горожан собирали бенефисы профессиональных актеров В.П. Полторацкого, Н.А. Вронского, Давыдова, Далматова и других. Как отмечали современники, несмотря на то, что Владикавказ «относительно цифры населения очень невелик», в нем все же была публика, которая наполняла и театр, и оба клуба, и домашние вечера, и маскарады [17,6-11].

Посещение спектаклей стало частью досуга городской элиты. Эта престижная форма времяпрепровождения была недоступна горожанам из-за высокой стоимости билетов. В Городской думе ставился вопрос о включении в бюджет определенной субсидии театру на устройство спектаклей для малоимущих горожан. В конце 1890-х годов городской театр дал несколько спектаклей для малоимущих, для студенческой молодежи города. Для учащихся ставились бесплатные пьесы из русской классики. Антрепренер Никулин поставил четыре спектакля для неимущих горожан «Бедность не порок», «Князь Серебряный», «На бойком месте», «Ревизор» с символической платой за вход в несколько копеек. Пресса отмечала небывалый успех - театр был переполнен.

Такие же «народные» спектакли ставил антрепренер Иван Алексеевич Ростовцев. Г. Апресян писал, что он «впервые в практике Владикавказского театра ввел общедоступные спектакли», билеты на которые стоили от 7 до 55 копеек. При всех заслугах Ростовцева все же стоит заметить, что он работал во Владикавказском театре только два года в 1911-1913 годах и всего лишь повторил опыт своих 
предшественников. Правда, ему удалось достичь успеха: огромное число желающих попасть на спектакли создавало угрозу общественному порядку и требовало вмешательства городской полиции. Спрос на билеты был так велик, что администрация подняла цены на них до 1 p. 30 копеек [18,32].

В октябре 1897 года в городском театре состоялся дневной спектакль для учащихся местных учебных заведений. Труппой К.К. Маврина во главе с ним и госпожою Анненской была разыграна известная классическая пьеса «Уриэль Акоста». Пресса отмечала, что театр был переполнен учащимися. В антрактах играл ученический оркестр $[19,11]$.

Стремление к приобщению широкой публики к театральному искусству вряд ли стоит связывать с частными инициативами. За этой социальной акцией повсеместно стояли городские власти, реализовывавшие культурную политику государства.

В то же время в репертуаре театра выделялись спектакли «только для интеллигенции». Группа актеров под управлением В.В. Никулина, дававшее бесплатные представления ученикам, считало, что «салонная публика» должна оценить спектакли, не пользующиеся популярностью у простых горожан из-за сложности сюжета. Таким спектаклем считалась, например, комедия Мольера «Тартюф» $[20,126]$. Владикавказцы имели возможность видеть на сцене городского театра знаменитую княжну Елену Тарханову в спектакле «Травиата».

В 1889 году «Терские ведомости» отмечали, что «в отношении общественных развлечений истекший год отличался от предыдущих лет тем, что вместо опереток, успевших уже надоесть многим театралам, на сцене нашего театра появилось товарищество артистов, идут драмы и комедии с весьма удачным подбором драматических сил» $[21,1]$.
K началу XX века театральная жизнь города заметно оживилась. Дирекция В.Ф. Аничковой-Ивановой часто организовывала гастроли малоросского театра, в городе побывало товарищество артистов императорских Санкт-Петербургских театров, бенефисы известных актеров восторженно воспринимались публикой.

По театральным постановкам многие горожане знакомились с произведениями русских классиков, среди них «Дядя Ваня» Чехова, «Маскарад» Лермонтова, «Горе от ума» Грибоедова, «На дне» и «Дети солнца» Горького, «Плоды просвещения» Толстого; не обходиди вниманием и зарубежную литературу, например «Наполеон и Жозефина» Бара, «Коварство и любовь» Шиллера, «Тартюф» и «Дон-Жуан» Мольера [22,5; 23,$254 ; 24,143 ; 25: 66,108,175 ; 26,164 ; 27: 212$ 214]. На сцене театра ежегодно выступали драматические труппы. Большим успехом пользовались гастроли артистов М. Савиной, М. Петипа, Ф. Горева, братьев Адельгейм. Ежегодно после окончания театрального сезона в театре давались спектакли, оперетты украинской труппы или постановки местных любителей. В феврале 1910 года в городском театре труппою 3.А. Малиновской была разыграна пьеса А.П. Чехова «Дядя Ваня», посвященная 50-летнему юбилею автора. Часть сбора была передана Ольгинской женской гимназии на удовлетворение нужд малообеспеченных учениц. Редкая театральная постановка обходилась без участия местных любителей. Среди них были свои знаменитости - Аптекман, Труффи, Атаров и другие. Любительские спектакли чаще всего бывали благотворительными. Они устраивались в пользу городских приютов, культурно-просветительских учреждений. В 1883 году любительский ученический театральный кружок был открыт в Лорис-Меликовском училище $[28,176]$. 
Родительские комитеты учебных заведений устраивали благотворительные вечера в пользу неимущих учеников, где кроме концертов и лотереи, как правило, ставились небольшие пьесы и водевили. Владикавказские студенты ставили спектакли в пользу «несостоятельных» учеников. В 1896 году на сцене городского театра прошел любительский спектакль в поддержку общественной библиотеки по произведению Островского «Бедность не порок», после которого любители разыграли водевиль «Чашка чаю» [19,34]. В октябре того же года городской музыкально-драматический кружок любителей поставил комедию А.С. Грибоедова «Горе от ума» в двух действиях и «Летние картинки» Н.И. Гнедича $[18,11]$. Местное городское общество было очень отзывчивым на благотворительные мероприятия и активно посещало любительские спектакли. В среде молодежи появилось новое развлечение - устройство домашних спектаклей.

Городской театр Владикавказа способствовал появлению осетинского, армянского, грузинского, еврейского драматических кружков. Кроме культурного просветительства они выполняли функцию внутриэтнической коммуникации, удовлетворяя потребности людей в земляческом общении, что было особенно актуально в условиях иноэтничной среды. Они содействовали развитию городской общественно-культурной среды.

Осетинский кружок любителей театрального искусства ставил спектакли на осетинском и русском языках. Особой популярностью у зрителей пользовалась драма «Хазби» Е. Бритаева, оперетка «Фаризат» А. Кубалова, «Дети гор» Д. Кусова, «Осетины в России» Хубаева. В числе первых актеров-любителей осетин был Коста Хетагуров. В конце 1880-х годов он начал устраивать в городе спектакли и «живые картины», выступал в качестве актера и оформителя сцены, а вскоре за- вершил работу над первым вариантом пьесы «Дуня», где ставил проблему равноправия женщин.

К постановкам на осетинском языке печатались программы с кратким содержанием на русском языке. Спектакли получали высокую оценку в местной прессе. По поводу драмы «Хазби» «Терские ведомости» отмечали, что по содержанию и по «количеству действующих лиц она превосходит все, что доселе появлялось в этом роде на осетинском языке» В постановке осетинской пьесы «Дети гор» Д. Кусова принимал участие Евгений Вахтангов - выдающийся мастер театрального искусства, тогда еще гимназист, активный участник любительских кружков. Спектакли ставились в благотворительных целях, для создания фонда по изданию газеты на осетинском языке, для оказания помощи осетинской молодежи, обучающейся в России, а также для общегородских нужд $[28,96]$.

В 1906 году горожанка Н.Е. Калоева подала генерал-губернатору заявление с просьбой разрешить ей устроить благотворительный спектакль на осетинском языке в «пользу недостаточных учащихся местных осетин». В 1913 году в чиновничьем клубе прошла пьеса «Вследствие воровства» на осетинском языке (сочинение Томаева). Сбор с этой благотворительной акции был передан осетинскому Ольгинскому женскому приюту. Проходили спектакли и в пользу осетинской церковно-приходской школы $[29,48$; 30:25,40;31,3].

На постановки театрального кружка собирались не только городские осетины, съезжались и сельские жители. Иногда представления завершались осетинскими танцами, а со временем, спектакли стали сопровождаться декламацией стихотворений, лотереей-аллегри, «летучей» почтой, европейскими танцами и другими современными формами городской культуры. Осетинский драматиче- 
ский кружок пользовался большой популярностью среди горожан. В 1909 году Х. Дзасохов обратился к Начальнику Терской области с ходатайством о разрешении сформировать осетинскую труппу, которая давала бы спектакли по всей Осетии. А священник Цомаев в 1913 году просил Управление железной дорогой разрешить осетинским любителям проехать на гастроли в Ростов. Эти предложения не нашли поддержки. Осетинская труппа гастролировала в Тифлисе, где в театре Ветцеля ставила спектакль «Лучше смерть, чем позорная жизнь» и одноактную комедию Е. Бритаева «Уарасей дзау».

Большой популярностью в городе пользовался армянский драматический кружок, в котором наряду с любителями периодически работали профессиональные актеры - Сардарянц, Зарифян, Абрамянц. С их участием были поставлены самые популярные спектакли «Шушаник», «Борьба армян с персами», комедия «Хатабала», водевиль «Особый вечер в деревне». Постановки проходили в армянском церковно-приходском училище, в доме горожанина Киракозова, на сцене городского театра. Вырученные средства использовались армянским благотворительным обществом. Позднее было основано армянское литературно-художественное общество по инициативе Е.Г. Караханова, Г.Я. Каплановой, Е.В. Тер-Асатурова, Л.П. Гукасянца и С.П. Мамулянца.

Еврейский община города также основала свой театральный кружок. На родном языке были поставлены драмы «Жертва Исаака», «Мирра Эфрос», водевиль «Поздравляю», часто разыгрываемый еврейской молодежью. Большая часть спектаклей была поставлена на русском языке по произведениям Лермонтова, Чехова. Кружок имел большую зрительскую аудиторию. Сбор со спектаклей и литературно-музыкальных вечеров использовался не только для нужд еврейского общества, но и на общегородские мероприятия. В 1899 году, например, в пользу владикавказской общественной библиотеки был поставлен спектакль «Шельменко-денщик» (комедия Квитко-Основьяненко) [32,27].

Любительские театральные, музыкальные и художественные кружки появились в Грозном, Кизляре, в начале XX века возникли Екатеринодарская и Нальчикская театральные труппы. С 1894 года в городе Майкопе ставил спектакли артистический Кружок любителей-интеллигентов. Большим событием в культурной жизни Майкопа было открытие в 1898 году Пушкинского народного дома, где работала труппа артистов-любителей «Майкопский артистический кружок», постановки которого пользовались неизменным успехом. Активную культурную и благотворительную практику имело «Общество любителей театрального искусства» в городе Грозном, основанное в 1877 году. На развитие сценического и музыкального искусства городов Северного Кавказа большое влияние оказывали гастроли многих замечательных артистов и музыкантов, театральных коллективов, приезжающих из Москвы и Петербурга и других городов [33].

Деятельность национальных театральных кружков стала активной сферой межэтнического взаимодействия: грузинское общество предоставляло осетинскому драматическому кружку зал своего училища для постановки спектаклей; для городской интеллигенции стало традицией посещать спектакли, знакомиться с творчеством друг друга, оказывать взаимную поддержку. Например, татарская община не могла своими силами организовать благотворительный вечер в пользу мусульманской школы. Но при содействии и активном участии армянских актеров-любителей в 1908 году были поставлены впервые, а затем ежегодно проводились постановки пьесы «Старая Тур- 
ция», оперетты 3. Гарин-Бекова «50-летний юноша» и другие. Такую же помощь оказывали осетины и другие любители при постановке первой ингушской пьесы «Сали» (сочинение есаула Козлова). О наличии интенсивных межэтнических контактов говорит, например, такое объявление, напечатанное в «Терских ведомостях»: «28 февраля в здании Общества распространения грамотности среди грузин труппою русских драматических артистов при участии Херувимовой и Горбачевского будет дан спектакль в пользу Владикавказского греческого училища. Представлено будет: «Еврей» и водевиль «Школьная пора» [26,32; 34,24; 24,57] .

«Местное по делам об обществах и союзах Присутствие» в начале XX века перестало регистрировать национальные драматические кружки, а циркуляр МВД предписывал проверять все «инородческие» общества на предмет угрозы общественному спокойствию. Официальной причиной отказа в регистрации культурно-просветительских национальных обществ объявлялось опасение, что они могли вызвать «национальную обособленность». Театральные кружки, выполняя функцию внутриэтнической коммуникации, способствовали не только распространению российской, но и развитию национальной культуры. Этот не прогнозируемый «побочный эффект» не вписывался в культурную политику российской администрации, особенно в годы послереволюционной реакции.

Достаточно эффективным средством идеологического влияния становился кинематограф. Первые синематографы и кинотеатры на Северном Кавказе появились во Владикавказе - кинотеатр «Пате» (1906 г.) названный в честь крупнейшего киномонополиста Шарля Пате, «Гигант» (1913 г.), электробиографы «Модерн». «Lux Roma» братьев Риччи, «Фантазия», «Электро». Вслед за Владикавказом основанием кинематографа занялись Кизляр и Грозный, Хасав-Юрт и Георгиевск, Пятигорск и Нальчик.

Распространение синематографа, или как его называли «волшебного фонаря» началось с учебных заведений и «народных чтений». Значительная часть репертуара в своей содержательной части, носила патриотичный характер - «Песни Кольцова», «В турецкой неволе», «Начало христианства на Руси, «Оборона Севастополя», «Кто были наши предки и как они жили», «Нашествие татар», «Жизнь Божьей матери», «Покорение Казани», «Александр Невский», «Отечественная война» и др.

Особым жанром кино в России была «царская» хроника, начало которой положено съемками коронации Николая II и продолжалось вплоть до революции 1917 года, во всех российских регионах. В деятельности кинотеатров особое внимание уделялось знаменательным датам российской истории. Так, 26 августа 1912 года, когда Россия отмечала 100-летие победы в Бородинском сражении, все местные кинотеатры были оборудованы декорациями и иллюминациями. В течение всего дня демонстрировали «Пожар в Москве», «Смоленскую битву», играл военный оркестр.

Владикавказская городская управа в июне 1915 года приняла решение об устройстве в городском театре «народного синематографа», доходы с деятельности которого должны были поддержать семьи военных. Власти предвидели «порядочный доход», возможность дать «разумное развлечение для народа», материально поддержать «семейства запасных и ратников», и установили цены, более низкие по сравнению с частными синематографами, справедливо полагая, что «народ, зная главную цель открытия городского синематографа, тем охотнее будет его посещать, неся трудовую копейку на доброе дело призрения семейств тех лиц, которые доблестно стоят против 
врага, защищая свободу и целость России» [35].

Посещение кинотеатров становилось весьма популярным способом проведения досуга. Сложно не согласиться с авторами, связывающими успешное развитие кинематографа с прямой финансовой выгодой развивающегося кинематографического рынка России. Но репертуap и стремление властей привлечь как можно больше народа к новому виду досуга позволяют рассматривать кино как механизм интеграции северокавказских горцев в российское общество, формирования в сознании «новых граждан» сопричастности к истории и жизни страны.

На эту задачу работали и другие культурные институции. Во Владикавказе было основано отделение Императорского Русского музыкального общества, которое устраивало вечера камерной музыки, концерты. В 1906 году музыкальное общество подготовило большой праздник в честь памяти Глинки. При обществе был открыт любительский хор, а позднее - музыкальная школа [36,151]. Во Владикавказе действовало Общество распространения художественно-промышленных знаний, которое устраивало выставки картин, организовывало передвижные выставки в других городах - Пятигорске, Кисловодске. Обращает внимание тематика мероприятий, например, выставка картин местного иконостасного живописца Ковалева «Крушение Императорского поезда 17 октября 1888 года». «Помещенная в просторном зале с искусственным освещением, картина имела большой успех», - сообщалось в «Терских ведомостях» $[36,152]$. Неотьемлемой частью городской культуры были музеи - музей Терского казачьего войска, музей М.A. Шульца, известный экспозицией исторических и анатомических восковых фигур, Терский областной музей, музей Лебзина с восковыми фигурами, коллек- цией минералов с Урала и другие. Появление музеев было свидетельством того, что в образованных кругах городского общества осознавалась необходимость сохранения и изучения культурного наследия. Музеи представляли для этого широкие возможности $[36,153]$.

Большое место в досуге горожан занимала библиотека. Первые библиотеки в городах Северного Кавказа были недоступны широкому читателю. В 1893 году инициативная группа обратилась к Начальнику Терской области с ходатайством об открытии бесплатной библиотеки. Общественная библиотека не была бесплатной, но цены были невысокими, поэтому Городская дума и благотворительные организации неоднократно выделяли правлению общественной библиотеки денежные пособия. Среди малоимущих горожан Владикавказа было много желающих читать, за пять месяцев 1913 года библиотека-читальня имела 800 абонентов. В книжных фондах библиотек значились сочинения Пушкина, Лермонтова, Белинского, Некрасова, Добролюбова, Писарева, Салтыкова-Щедрина, Глеба Успенского [36,153-154].

Художественная культура как важный компонент исторического сознания активно использовалась в идеологии разных политических режимов. Например, Русский театр во Владикавказе после революции «при горячей поддержке Сергея Мироновича Кирова», организатора большевистской подпольной организации, стал первым Владикавказским советским театром; «товарищ Киров нередко встречался с актерами, а во время постановок бывал за кулисами театра, помогал театру советами» $[8,39]$. «Владикавказский театр, когда-то задуманный царскими полицейскими, как орудие постепенной русификации горских народов, - стал местом дружбы этих народов», - такой тезис появился в советском дискурсе $[8,43]$. 
Советская власть также высоко ценила возможности кинематографа, активно используя «важнейшее из искусств»; В.И. Ленин считал его таковым в условиях массовой неграмотности населения. Влияние кино на общественные настроения советских людей сохранялось достаточно длительное время, пока эта функция не перешла на новые технологические платформы, прежде всего, телевидение. Творчество советских деятелей культуры - актеров, художников, композиторов, писателей и др. использовалось для создания образов, конструирующих общественное сознание.

Сегодня эта проблема актуализирована государственной национальной политикой, задачами которой являются согласование государственных и национально-культурных интересов народов Российской Федерации, совершенствование межэтнических отношений, создание условий для утверждения общегражданской идентичности - российской нации. С этой целью в проекте Федерального закона «Об основах государственной национальной политики Российской Федерации» предусмотрены программы национально-культурного развития субъектов Российской Федерации и отдельных народов Российской Федерации, а также система мер, направленных на расширение сотрудничества и духовное взаимообогащение граждан всех национальностей. При этом признается консолидирующая роль российской культуры и русского языка, которая способствует сохранению единства и целостности многонационального Российского государства. Медийность современного общества имеет мощный ресурс для пополнения коллективной культурной памяти и исторической традиции новыми формами и символами.

1. Культурная политика России на Кавказе как фактор утверждения российской государственности и общероссийской идентичности. Материалы научного семинара. Владикавказ, 2016.

2. Дзалаева К.Р. Русская школа как основной механизм утверждения общероссийской идентичности в Осетии во второй половине XIX - начале XX в. // Известия COИГСИ. 2016. Вып. 21(60). С. 47-54.

3. Дзалаева К.Р. Библиотека как культурная потребность северокавказского социума в условиях формирования общероссийской идентичности (вторая половина XIX - начало ХХ в.) // Известия СОИГСИ. Школа молодых ученых. 2014. № 12. С. 21-27.

4. Канукова 3.В. Православие в формировании российской государственности и общероссийской идентичности в Осетии (конец XVIII - начало XX в.) // Известия СОИГСИ. 2016. Вып. 20(59). С. 40-50.

5. Туаева Б.В. Локальная история: особенности культурной и общественной жизни городов Северного Кавказа во второй половине XIX - первой трети XX веков. Владикавказ, 2010.

6. Кобахидзе Е.И. Русский язык в образовательной практике кавказской начальной школы в XIX - начале XX в. // Культурная политика России на Кавказе как фактор утверждения российской государственности и общероссийской идентичности. Материалы научного семинара. Владикавказ, 2016. С. 42-55.

7. Кобахидзе Е.И. Ресурсы позднеимперской «русификации» на Северном Кавказе // Российская история. 2016. № 3. С. 74-82.

8. Апресян Г. Старейший театр на Кавказе. Орджоникидзе, 1939. 
9. История народов Северного Кавказа. М., 1988. Т. 2.

10. Гутиева Э.Ш. Осетинская интеллигенция в эпоху пореформенной модернизации.Автореферат диссертации на соискание ученой степени кандидата исторических наук. Владикавказ, 2009. С. 14-16.

11. Центральный государственный архив Республики Северная Осетия-Алания (ЦГА РСО-А). Ф. 11. Оп. 16. Д. 22.

12. ЦГА РСО-А. Ф. 12. ОП. 7. Д. 353.

13. ЦГА РСО-А. Ф. 12. Оп. 7. Д. 360.

14. Статьи неофициальной части «Терских ведомостей».1870

15. Терские ведомости, 1911.

16. Терские ведомости, 1913.

17. Терские ведомости, 1884.

18. Терские ведомости, 1897.

19. Терские ведомости, 1896.

20. Терские ведомости, 1889.

21. Терские ведомости, 1901.

22. Терские ведомости, 1902.

23. Терские ведомости, 1903.

24. Терские ведомости, 1906.

25. Терские ведомости, 1910.

26. Терские ведомости, 1914.

27. Статьи неофициальной части «Терских ведомостей». 1883.

28. Гутиева Э.Ш. Социокультурное развитие пореформенной Осетии (вторая половина XIX - начало XX в.). Владикавказ, 2013.

29. Терские ведомости, 1909.

30. Терские ведомости, 1913.

31. Жизнь Северного Кавказа, 1906.

32. Терские ведомости, 1899.

33. Туаева Б.В. Театр в социокультурной сфере северокавказских городов в пореформенный период // Актуальные проблемы гуманитарных наук. Материалы 2-й региональной конференции. Владикавказ, 2009. С. 182-187

34. Терские ведомости, 1916.

35. Дзалаева К.Р. Утверждение общероссийской идентичности на Северном Кавказе средствами кинематографии (вторая половина XIX - начало XX вв.) // Современные проблемы науки и образования. 2014. № 6. С. 1500.

36. Канукова 3.В. Старый Владикавказ. Историко-этнологическое исследование. Владикавказ, 2008. 